\title{
Potential of Proposed Open-Cycle OTEC Experiments to Achieve Net Power
}

Harold F. Link

Brian K. Parsons

June 1986

Prepared for Oceans ' 86

Washington, DC

23-25 September 1986

Prepared under Task No. 4014.31

FTP No. 586

Solar Energy Research Institute

A Division of Midwest Research Institute

1617 Cole Boulevard

Golden, Colorado 80401-3393

Prepared for the

U.S. Department of Energy

Contract No. DE-AC02-83CH10093 


\section{NOTICE}

This report was prepared as an account of work sponsored by the United States Government. Neither the United States nor the United States Department of Energy, nor any of their employees, nor any of their contractors, subcontractors, or their employees, makes any warranty, expressed or implied, or assumes any legal liability or responsibility for the accuracy, completeness or usefulness of any information, apparatus, product or process disclosed, or represents that its use would not infringe privately owned rights.

\section{Printed in the United States of America}

Available from:

National Technical Information Service

U.S. Department of Commerce 5285 Port Royal Road Springfield, VA 22161

Price: Microfiche A01 Printed Copy A02

Codes are used for pricing all publications. The code is determined by the number of pages in the publication. Information pertaining to the pricing codes can be found in the current issue of the following publications, which are generally available in most libraries: Energy Research Abstracts, (ERA); Government Reports Announcements and Index (GRA and I); Scientific and Technical Abstract Reports (STAR); and publication, NTIS-PR-360 available from NTIS at the above address. 
Potential of Proposed Open-Cycle OTEC Experiments to Achieve Net Power

Harold F. Link

Brian K. Parsons

\author{
Solar Energy Research Institute \\ 1617 Cole Boulevard \\ Golden, Colorado 80401
}

\begin{abstract}
Researchers at the Solar Energy Research Institute (SERI) conducted systems analysis studies to determine the potential of various experiments to produce net power using the Claude open-cycle ocean thermal energy conversion (OTEC) power system. The proposed experiment test site is to be the Natural Energy Laboratory of Hawaii at Keahole Point. We found that net power is unlikely to be produced in experiment sizes that use less than about $195 \mathrm{~kg} / \mathrm{s}$ (3000 gpm) of cold water, and that flow rates of $420 \mathrm{~kg} / \mathrm{s}(6500 \mathrm{gpm})$ are necessary to achieve a net-power production of at least one-half the gross-power output of the experiment.
\end{abstract}

\subsection{INTRODUCTION}

\subsection{Background}

DOE initiated research on the extraction and conversion of the ocean thermal energy resource using an open-cycle process late in FY 1978 with the funding of a task to assess the feasibility of this technology to produce costeffective electrical power. The original SERI studies, supported by the results of subcontracted studies at the Colorado School of Mines, Westinghouse Corporation, and University of Massachusetts, scale plants based on this technology could be economically viable if the main assumptions in the studies were valid. A research program to develop data and analytical methods to refine and support these assumptions was begun in FY 1980.

Research conducted over the last 6 years has provided data and methods that were recently applied to a new system study of the open-cycle technology. The Florida Solar Energy Center (FSEC) and Creare R\&D, Inc. showed that all the major assumptions made in the early feasibility studies had been conservative. Thus open-cycle OTEC is even more promising than first projected. Their results indicated that smaller plants (5-15 $\left.\mathrm{MW}_{e}\right)$ are nearly as economical to build as larger plants. This result is promising since many tropical-island communities do not require large power-generating facilities.

One primary advantage of open-cycle OTEC is the use of an inexpensive, compact, and efficient direct-contact evaporator in place of the large, metal, conventional evaporator required in closed-cycle OTEC systems. A direct-contact condenser with similar advantages can also be used in the open-cycle system if the plant site has no need for additional fresh water. If a freshwater by- product is desired, a surface condenser can be used in the open-cycle system since the flash evaporator acts as a distillation unit. In many locations, the value of the fresh water may well offset the additional cost and possible degradation in performance associated with the surface condenser.

Although laboratory tests have verified many of the data and analysis methods used by the FSEC/Creare analysis, experiments to date have only been conducted on individual components, primarily in fresh water. Correlations of the performance of the direct-contact heat exchanger using seawater for open-cycle OTEC are still considered preliminary. We studied different experiments to determine their potential to verify that the system operates as expected and to resolve three principal uncertainties:

- Performance of the heat exchanger using seawater

- Performance of the low-fressure steam turbine

- Effect of interaction among components on system performance.

In one experiment, described by Shelpuk, ${ }^{5}$ equipment was sized to take advantage of a planned upgrade of the Natural Energy Laboratory of Hawaii's Seacoast Test Facility. More recently, we investigated other sizes of experiments to determine:

- Potential to resolve the uncertainty of heat-exchanger performance under various operating conditions of interest

- Potential to produce net power

- Size requirements of seawater-supply and vacuum vessels.

This paper describes the systems analysis efforts to estimate the potential of these experiments to produce net power.

\subsection{Open-Cycle System Description}

Figure 1 shows a. schematic of the basic open-cycle system. Warm, tropical seawater $\left(25^{\circ} \mathrm{C}\right)$ is pumped from near the ocean's surface into an evacuated evaporator chamber where the pressure is lower than the corresponding saturation condition of the entering seawater. Flash evaporation results, cooling the seawater 


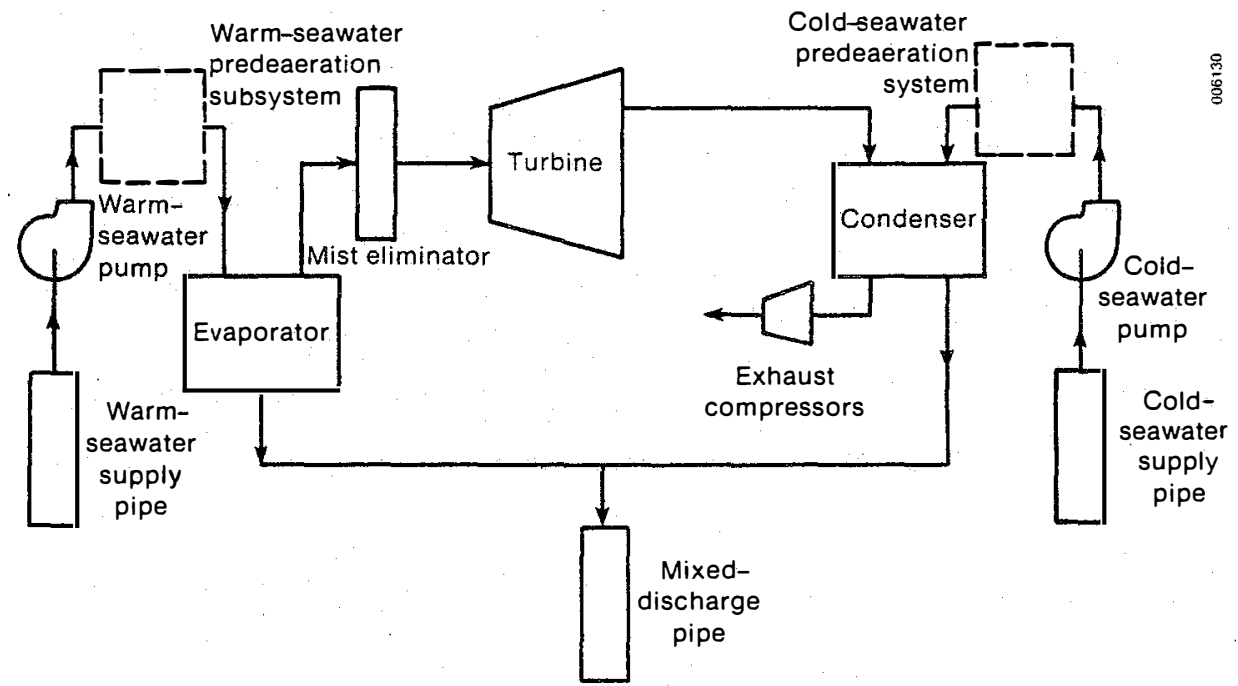

Figure 1. Claude open-cycle OTEC system

and converting a small portion of it $(20.5 \%)$ to lowpressure steam.

The colder seawater $\left(20^{\circ} \mathrm{C}\right)$ is then discharged back into the ocean. For some evaporator designs, the violent boiling process may entrain small droplets of seawater in the steam. A mist-removal device eliminates these droplets before they can corrode or erode the turbine blades. About $30 \%$ of the gross power of the open-cycle system is used to drive the seawater pumps and the exhaust compressors. The remaining net power is available to a utility power grid.

Cold seawater $\left(\sim 5^{\circ} \mathrm{C}\right)$ is pumped from ocean depths of around $1000 \mathrm{~m}$ to condense about $98 \%$ of the steam downstream of the turbine. In comparison to conventional steam power systems, the steam contains a significantly greater content of noncondensable gases. These gases, primarily oxygen and nitrogen, are dissolved in seawater and released in the low-pressure conditions of the evaporator and direct-contact condenser. The presence of these gases decreases the efficiency of the condenser and requires that a sizable compressor be used to exhaust them from the vacuum chamber.

Some of the dissolved noncondensable gases may be removed from the warm and cold seawater before it enters the main power system. These optional seawater predeaerators operate at pressures greater than the seawater vapor pressure but low -enough to allow gas desorption.

More information on the computer model used to study this system is available from the proceedings of OCEANS $185^{6}$ as well as from SERI technical reports.'

\subsection{Configuration of Experimental Apparatus}

The experimental-scale, open-cycle OTEC plant being considered for construction at the Seacoast Test Facility would represent a commercial-scale plant in many respects. The flow paths and components shown in Figure 1 would be used for the experimental plant; however, practical and cost considerations require that, in some aspects, the experimental plant would look somewhat different from a commercial plant. The most apparent difference is that a commercial plant would incorporate the heat exchangers, steam passages, and turbine housing directly into a reinforced concrete vacuum structure. The experimental plant, on the other hand, would consist of a number of epoxy-coated steel vacuum vessels connected by appropriately sized pipes (Figure 2).

The second difference is that the experimental plant might be located at ground level even though optimum performance is achieved when the heat exchangers are raised to the barometric height. This variation from a commercial design is discussed later.

Finally, while a commercial plant might use surface condensers to produce fresh water, present studies indicate that the lowest cost plant for energy production would use direct-contact condensers. For the purposes of this study, we considered only direct-contact condensers.

\subsection{SITE CHARACTERISTICS AT THE SEACOAST TEST FACILITY}

These experiments will be conducted at the Natural Energy Laboratory of Hawaii's Seacoast Test Facility at Keahole Point on the big island of Hawaii. This facility is presently unequalled in its ability to provide both warm and cold seawater for a variety of OTEC and spin-off experiments. Pipes $0.3 \mathrm{~m}$ (12 in.) in diameter deliver up to $130 \mathrm{~kg} / \mathrm{s}(2000 \mathrm{gpm})$ of warm water and $65 \mathrm{~kg} / \mathrm{s}$ (1000 gpm) of cold water continuously to experiments in corrosion and biofouling, as well as supplying water for a number of mariculture operations. In a planned upgrade, the water-flow capability of the facility will be enhanced with new seawater pipes and pumps, in part, to support experiments in open-cycle component and system performance.

A major element of the cost of any OTEC plant is the piping required to bring cold water to the plant. In this study, therefore, the size of the experiment was characterized by the cold-water flow. The cold-water flow rates considered in this study, $30-4750 \mathrm{~kg} / \mathrm{s}$ (500-7500 gpm) include the current flow capabilities at the Seacoast Test Facility. 


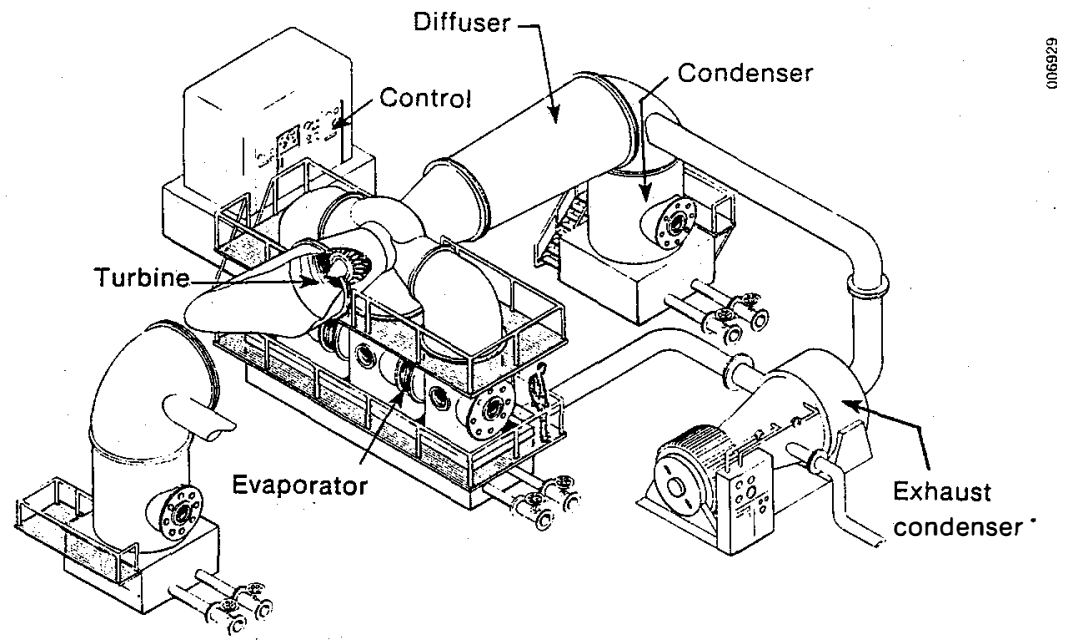

Figure 2. Conceptual layout of a 165-kW experiment

\subsection{CONSIDERATIONS IN MODELING EXPERIMENTAL-SCALE PLANTS}

\subsection{Major System Trade-Offs}

The major trade-offs in an open-cycle OTEC system can be characterized by the temperature distribution in the plant and the velocities in the seawater pipes. For example, if the steam temperature in the evaporator is increased, less steam per unit of warm seawater will be produced but the turbine will extract more power per unit of steam. Similarly, if the temperature at the turbine outlet is increased, power output will be decreased but less cold water will be required. The optimum temperature distribution is normally adjusted to minimize plant capital costs per net energy production and is, therefore, highly dependent on the algorithms used to characterize component costs. The model uses cost algorithms representative of plants in the $10-\mathrm{MW}$ size range that would need to be adjusted to estimate costs reliably for small experiment-scale plants. Therefore we optimized a $10-\mathrm{MW}$ e plant at the seawater resource temperatures characteristic of the Seacoast Test Facility and maintained this temperature distribution throughout our study.

Seawater-pipe water velocities provide the second major area of trade-offs in a system study. Increasing water velocity decreases the size and cost of the corresponding pipe at the expense of increased pumping power. In a $10-\mathrm{MW}$ size plant, optimum water velocities are around $2.2 \mathrm{~m} / \mathrm{s}(7.2 \mathrm{ft} / \mathrm{s})$. In smaller-scale plants, however, we found that lower velocities were required to prevent excessive pressure losses in the seawater supply and discharge pipes. We used velocities of $1.1 \mathrm{~m} / \mathrm{s}(3.6 \mathrm{ft} / \mathrm{s})$ for the experimental-scale pipes.

\subsection{Mechanical Efficiency}

One aspect of this study defines the appropriate efficiencies for mechanical components in the experiment. These components include the steam turbine, warm and cold seawater pumps, and the compressor to remove noncondensable gases. In each of these components, losses tend to increase with decreasing size for a number of reasons. For example, viscous losses tend to increase in smaller sizes because a higher percentage of the seawater or steam contacts the walls of the flow passages. In addition, because operating costs become more of a concern with large components, manufacturers can justify increased attention to design and fabrication details in larger components.

After investigating some correlations of component efficiency to size, we selected a Reynolds number dependency as described by Balje.' Balje shows how the efficiency of various turbines decreases from a nominal efficiency as the component Reynolds number decreases from $5 \times 10^{6}$. We selected an intermediate curve from the family he presented as representative of the mediumspecific speed and low-pressure ratio of open-cycle turbines.

Since the Reynolds number is proportional to the characteristic diameter of the component, and since the diameter is proportional to the square root of the volumetric flow, we derived the correlations of component efficiency to cold-seawater flow rate as shown in Figure 3.

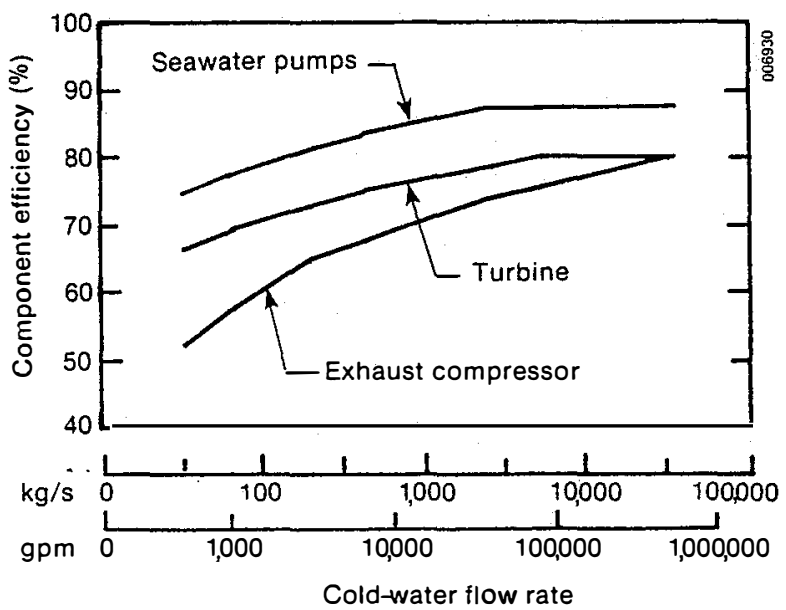

Figure 3. Mechanical efficiencies as a function of plant size 


\subsection{Pressure-Loss Factors}

A second factor that affects the performance of smallscale plants is intercomponent pressure loss of both steam and seawater. Because of the large volumetric flow rates in both steam and seawater flows, the piping system is optimally formed from appropriately configured walls and passageways in the plant structure. These passageways would probably consist of reinforced concrete with additional smoothing of corners and transitions using either ferrocement or fiber-reinforced plastic. In a smallscale experimental plant, however, a simpler and lessexpensive construction technique is a more conventional steel piping system.

The large vacuum-chamber components, such as heat exchangers, are tanks that are connected with either large-diameter pipes or, preferably, fitted and faired elbows that are close to the same diameter as the heatexchanger tanks. The turbine/diffuser adds significantly to the cost of the vacuum chamber not only because of its size but because its conical shape complicates its fabrication. Adding to the cost of the experimental-scale plant is the desirability of maintaining the heat exchangers at their appropriate barometric height. This requires placing the entire vacuum-chamber assembly on top of one or more towers. To minimize the cost of this structure, the smaller-scale experiments are likely to crowd the major components together on one tower. The connecting piping would not be optimized for minimum pressure losses and, in the smallest sizes, the turbine diffuser perhaps would be eliminated.

As a result, steam pressure-loss factors for the smallscale plants are three times greater than those estimated for a representative $10-\mathrm{MW}$ plant. In a plant requiring $195 \mathrm{~kg} / \mathrm{s}(3000 \mathrm{gpm})$ of cold water or less, no diffuser would be used.

Similarly, the piping system for the seawater flows differs significantly from that expected to be used in a $10-\mathrm{MW}$ plant. The existing piping system at the Seacoast Test Facility already has a number of elbows and valves that would be avoided in a full-scale plant. In addition, routing the seawater from the the existing pipes to the heat exchangers would require an additional isolation valve and probably three more $90^{\circ}$ elbows. We estimated the additional pressure-loss factors for these piping components to be two to three times that which might be expected in a full-scale commercial plant.

\subsection{Resource Seawater Temperatures}

A final factor in estimating the performance of smallscale plants is the heat transfer between the incoming seawater and the ambient fluids. In the warm seawater, heat is lost to the air as the water is routed across the shore to the test facility. More significantly, the cold seawater gains heat not only from the air but from the surrounding warm seawater in the shallow-water portions of its supply pipe. In large-scale plants, this heat transfer has a negligible effect on the temperature of incoming seawater because the volume-to-surface area of the supply pipes is so large and because much of the pipe would be buried. For the purposes of this study, we found that the larger experiments that require at least $420-\mathrm{kg} / \mathrm{s}$ (6500-gpm) cold-water flows would suffer negligible heat transfer between the supply seawater and ambient fluids. At lower flow rates, sufficient heat transfer would occur in the experiments so that the total temperature difference between cold and warm seawater would decrease from a possible maximum of $19.0^{\circ}$ to $17.5^{\circ} \mathrm{C}$ $\left(34.2^{\circ}\right.$ to $\left.31.5^{\circ} \mathrm{F}\right)$.

\subsection{Barometric Height Considerations}

Since the direct-contact evaporator and condenser operate at subatmospheric pressures of 2500 and $1500 \mathrm{~Pa}$ absolute ( 0.36 and 0.22 psia), respectively, minimum seawater pumping power is obtained when these components are located nominally $10 \mathrm{~m}(33 \mathrm{ft})$ above sea level. For example, in the evaporator seawater path, pressure losses in the warm-water supply pipe for desired flow rates are around $1500 \mathrm{~Pa}$, and pressure losses in the evaporator are $1700 \mathrm{~Pa}(0.24 \mathrm{psi})$. If the evaporator were placed at sea level, a valve would have to induce a pressure loss of around $96,000 \mathrm{~Pa}$ (13.9 psi) in the piping. The water would then have to be pumped out of the lowpressure chamber for discharge back into the ocean. The alternative is to raise the evaporator to barometric level so the elevation head is equal to the loss imposed by the valve. The head can then be recovered when the water is discharged from the chamber, and the pumping head and power are significantly reduced. Depending on configuration and control strategy, the barometric height can vary from around 8 to $12 \mathrm{~m}$ above sea level.

Placement at barometric height results in minimum seawater pumping power. In this case, pumping head is equal to the head losses in the intake and discharge piping plus. the heat-exchanger losses. If the heat-exchanger areas are large, as in a commercial-size plant, raising the heat exchanger from ground level to barometric height may not greatly affect the overall initial plant cost. For small-scale experimental piants, however, the fractional cost of raising the vacuum chambers to barometric height would be much greater. We evaluated the net-power penalty for location at less than barometric level and found that for the $420-\mathrm{kg} / \mathrm{s}(6500-\mathrm{gpm})$ size, $5 \mathrm{~kW}$ of net power were lost for every meter the condenser was lowered. Since the ground level at the experimental facility in Hawaii is around $4 \mathrm{~m}$ above sea level, the additional pumping power would consume $30 \%$ of the gross power in the experimental plant shown at ground level in Figure 2. This extra pumping power would decrease that experiment's net-power output to only $40 \mathrm{~kW}$ of the $165 \mathrm{~kW}$ delivered by the generator.

Since in this study we were considering how to obtain the highest net power for a given cold-water flow rate to validate our models, we noted that the heat exchangers should be located at barometric height.

\subsection{RESULTS}

Having characterized the input parameters for the system analyses as described in the previous sections, we calculated the net power for a number of experiment sizes. As discussed earlier, we used cold-water flow rate to characterize the experiment size. We calculated gross and net power for plants using cold-water flows of 30,65 , $195,420,2500$, and $5000 \mathrm{~kg} / \mathrm{s}$.

\subsection{Heat-Exchanger Performance}

Since a major purpose of building this experimental plant is to verify the performance of OTEC heat exchangers, we need to understand the effects of uncertainty in predicted 
heat-exchanger performance on net-power production Evaporator performance is characterized by effectiveness, which expresses how closely the outlet-steam temperature approaches the outlet-water temperature. Although the vertical-spout evaporator has repeatedly demonstrated a high effectiveness of 0.95 in laboratory experiments, we conservatively input a value of 0.90 in our baseline system runs. To judge the effect of a poor evaporator performance, we ran a case with an effectiveness of 0.80 . Net power was reduced by less than $5 \%$ of the baseline gross.

Similarly we considered the worst-case condenser performance where only 95\% of the steam was condensed (versus a baseline case of 98\%). Although this change appears small, it results in an exhaust compressor power requirement three times higher than in the baseline. This change also reduced net power by about $25 \%$ of the baseline gross. Figure 4 shows how a combination of a poor evaporator and a poor condenser reduces net-power production. Note that, for flows of less than $225 \mathrm{~kg} / \mathrm{s}$ ( $3500 \mathrm{gpm})$, the seawater pumps and exhaust compressor might consume more power than the turbine produces.

The geometry and operating conditions of the condenser strongly affect the amount of steam that a given condenser can eliminate. Rather than accept performance when only $95 \%$ of the steam is condensed, the experimenter can readily increase the height of a direct-contact condenser or change the size of the packing material. We have estimated that the experimental configuration could be altered for net-power experiments so that only a slight increase in cold-water pumping power would be required to achieve the baseline condenser performance. The combined effect of this increased pumping power and an evaporator effectiveness of 0.80 is shown by the lower bound of net power in Figure 5. By altering the condenser geometry, we have limited the loss of net power to only about $10 \%$ of the gross power.

\section{Major}

In the

chang

of

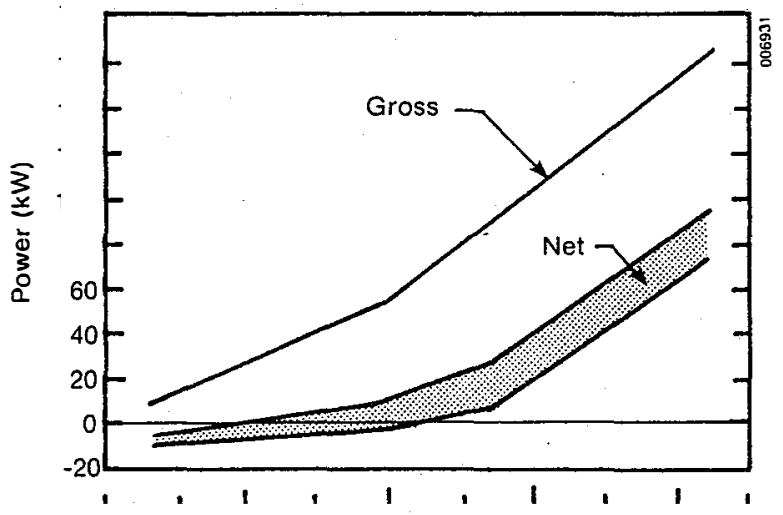

$\mathrm{kg} / \mathrm{s}$

gpr

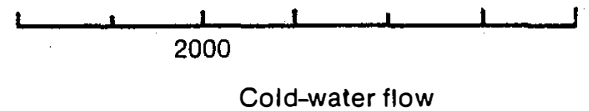

Figure 4. Net power with nominal and low fractions of steam condensed related to velocity in the seawater pipes and mechanicalequipment efficiencies. Figure 6 shows how changing the size of the seawater pipes for the $195-\mathrm{kg} / \mathrm{s}(3000-\mathrm{gpm})$ plant would affect the predicted net power of that plant. At the baseline conditions of $1.1-\mathrm{m} / \mathrm{s}$ velocity in each of the pipes, the net power ic $25 \mathrm{~L} / \mathrm{t} / \mathrm{m}$. Inrreasing the size of the warm-water or mixed-discharge pipes does not increase net power significantly; however, decreasing the size of either of these pipes or changing the cold-water pipe diameter would have a significant effect on net power.

Similarly Figure 7 shows how changes from the calculated mechanical efficiencies affect net power for the 3000 gpm plant. It is apparent that turbine efficiency has the biggest effect on power production. Improvements in the efficiency of the other components will not have as large an effect on net-power production. Improperly sized or low-efficiency components, however, could easily eliminate the potential to produce any net power.

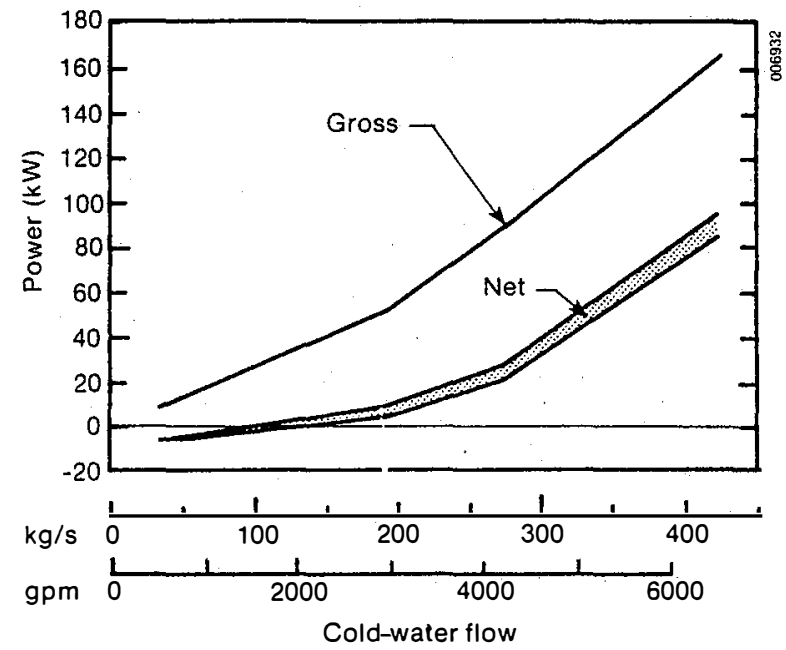

Figure 5. Net power with nominal and oversized condensers

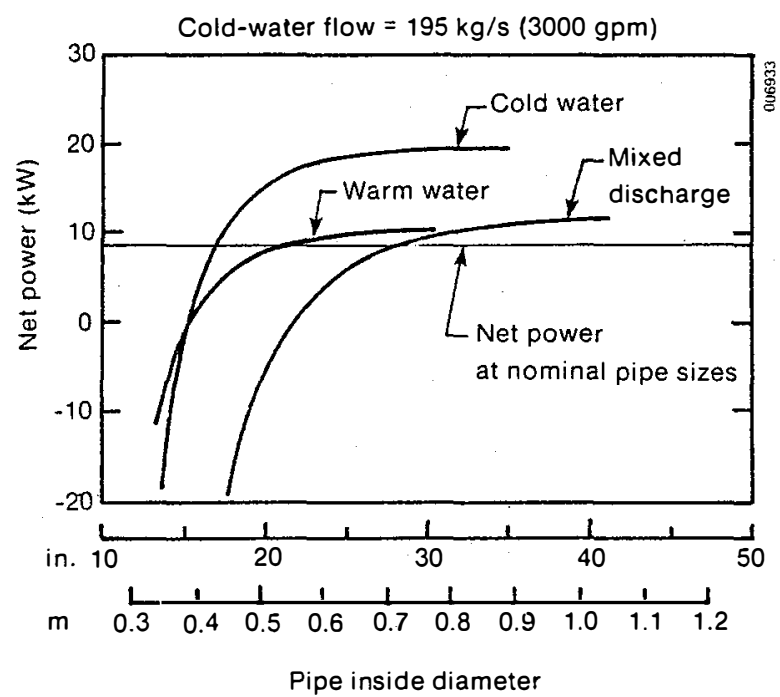

Figure 6. Effect of pipe size on net power 


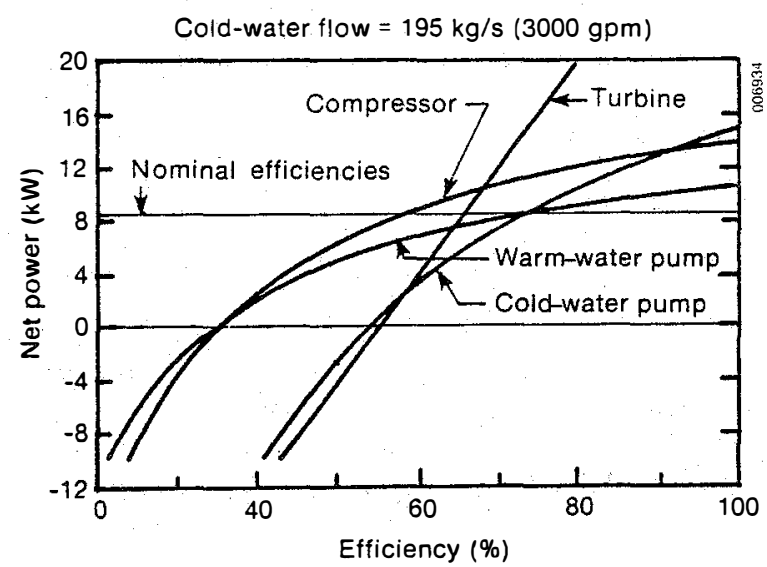

Figure 7. Effect of mechanical efficiency on net power

\subsection{CONCLUSIONS AND RECOMMENDATIONS}

Based on the results of this study, as shown in Figure 5, we found that net power is unlikely to be produced in experiment sizes that use less than about $3000 \mathrm{gpm}$ of cold water. A reasonable ratio of net to gross power is not achieved until the experiment size is increased to about $6500 \mathrm{gpm}$ where parasitic power losses absorb 50\% or less of the gross output of the plant. Critical characteristics of the experimental plant are:

- Location of heat exchangers at barometric height

- High-efficiency turbine

- Adequately sized seawater pipes.

While it is possible to realize net-power production in an experiment that uses as little as $195 \mathrm{~kg} / \mathrm{s}(3000 \mathrm{gpm})$ of cold water, uncertainties in component performance could easily eliminate net-power production at this size. We concluded that an experiment using $420 \mathrm{~kg} / \mathrm{s}(6500 \mathrm{gpm})$ would provide a more suitable margin of net power as well as a significantly better ratio of net to gross power.

\subsection{ACKNOWLEDGMENT}

We wish to acknowledge and express our gratitude to the Ocean Energy Technology Program of the Department of Energy, which sponsored this research.

\subsection{REFERENCES}

1. Watt, A. D., Mathews, F. S., and Hathaway, R. E., Open Cycle Ocean Thermal Energy Conversion, A Preliminary Engineering Evaluation, Final Report, Golden, CO: Colorado School of Mines, December 1977.

2. $100 \mathrm{MW}$ OTEC Alternate Power Systems, Final Report, Lester, PA: Westinghouse Electric Corporation, Power Generation Divisions, March 1979.

3. Boot, J. L., and McGowan, J. F., Feasibility Study of a 100 Megawatt Open Cycle Ocean Thermal Difference Power Plant, NSF/RANN/SE/GI34979/TR/74/3, Amherst, MA: Mechanical Engineering Department, University of Massachusetts, August 1974.

4. Valenzuela, J., et al., "Thermo-Economic Analysis of Open Cycle OTEC Plants," ASME paper 非84WA/SOL-24, presented at the ASME Winter Annual Meeting, December $1984^{\circ}$.

5. Shelpuk, B., "A 165-kW Open Cycle OTEC Experiment," SERI/TP-251-2725, Golden, CO: Solar Energy Research Institute, June 1985. Presented at the 12th Annual Intersociety Energy Conversion Engineering Conference, Miami Beach, FL, 18-23 August 1985.

6. Parsons, B. K., and Link, H. F., "System Studies of Open-Cycle OTEC Components," SERI/TP-253-2794, Golden, CO: Solar Energy Research Institute, September 1985. Presented at Oceans '85, San Diego, CA, 12-14 November 1985.

7. Parsons, B. K., Bhara:han, D., and Althof, J. A., Thermodynamic Systems Analysis of Open-Cycle Ocean Thermal Energy Conversion, SERI/TR252-2234, Golden, CO: Solar Energy Research Institute, September 1985.

8. Bharathan, D., Althof, J. A., and Parsons, B. K, Direct Contact Condensers for Open-Cycle Ocean Thermal Energy Conversion (OTEC) Applications, Volume 1: Analytical Modeling, Draft Report, SERI/RR-252-2472, Golden, CO: Solar Energy Research Institute, April 1985.

9. Balje, O. E., Turbomachines, A Guide to Design, Selection, and Theory, New York: John Wiley and Sons, 1981. 